\title{
An Experimental Study of the Performance of Isomorphically Zirconium-Substituted Mesoporous Alumina Supported Cobalt Catalysts in Fischer-Tropsch Synthesis
}

\author{
Sabar Simanungkalit, Mingming Zhu*, Gia Hung Pham, Zhezi Zhang, Dongke Zhang \\ Centre for Energy (M473), The University of Western Australia, Crawley, Australia \\ Email: *mingming.zhu@uwa.edu.au
}

How to cite this paper: Simanungkalit, S., Zhu, M.M., Pham, G.H., Zhang, Z.Z. and Zhang, D.K. (2022) An Experimental Study of the Performance of Isomorphically Zirconium-Substituted Mesoporous Alumina Supported Cobalt Catalysts in Fischer-Tropsch Synthesis. Advances in Chemical Engineering and Science, 12, 40-53.

https://doi.org/10.4236/aces.2022.121004

Received: November 23, 2021

Accepted: January 10, 2022

Published: January 13, 2022

Copyright $\odot 2022$ by author(s) and Scientific Research Publishing Inc. This work is licensed under the Creative Commons Attribution International License (CC BY 4.0).

http://creativecommons.org/licenses/by/4.0/

\section{(c) (i) Open Access}

\begin{abstract}
A series of mesoporous alumina (MA) supported cobalt (Co/MA) catalysts with MA isomorphically substituted by zirconium $(\mathrm{Zr})$ were synthesised and evaluated for their performance in the Fischer-Tropsch synthesis. The $\mathrm{Zr} /(\mathrm{Zr}$ $+\mathrm{Al}$ ) atomic ratios varied from $1 \%-15 \%$. A zirconium-impregnated Co/MA catalyst prepared by wet impregnation with a $\mathrm{Zr} /(\mathrm{Zr}+\mathrm{Al})$ atomic ratio of $5 \%$ was also evaluated to examine $\mathrm{Zr}$ incorporation's effect method. The catalysts synthesised were characterised using $\mathrm{N}_{2}$ adsorption-desorption, X-ray Powder Diffraction (XRD), Transmission Electron Microscopy (TEM), and X-Ray Photoelectron Spectroscopy (XPS). It was found that $\mathrm{Zr}^{4+}$ ions were incorporated into the framework of MA and kept intact up to a $\mathrm{Zr} /(\mathrm{Zr}+\mathrm{Al})$ atomic ratio of $5 \%$. The cobalt dispersion and reducibility were improved as the $\mathrm{Zr} /(\mathrm{Zr}+\mathrm{Al})$ atomic ratio increased to $50 \%$. The performance of these catalysts for Fischer-Tropsch synthesis was evaluated using a fixed bed reactor at temperature and pressure of $493 \mathrm{~K}$ and 20 bar, respectively. The feed syngas had an $\mathrm{H}_{2} / \mathrm{CO}$ ratio of 2, diluted with $10 \%$ Ar. For isomorphically $\mathrm{Zr}$-substituted $\mathrm{Co} / \mathrm{MA}$, the $\mathrm{CO}$ conversion and selectivity of diesel $\left(\mathrm{C}_{10}-\mathrm{C}_{20}\right)$ increased first and then decreased with increasing the $\mathrm{Zr} /(\mathrm{Zr}+\mathrm{Al})$ atomic ratio. The maximum $38.9 \%$ CO conversion and $34.6 \%$ diesel $\left(\mathrm{C}_{10}-\mathrm{C}_{20}\right)$ selectivity were obtained at $\mathrm{Zr} /(\mathrm{Zr}+\mathrm{Al})$ atomic ratio of $5 \%$. The isomorphic substitution method was better than the wet impregnation method in $\mathrm{CO}$ conversion and diesel selectivity.
\end{abstract}

\section{Keywords}

Cobalt Catalyst, Fischer-Tropsch Synthesis, Isomorphic Substitution, Mesoporous Alumina, Zirconium 


\section{Introduction}

The development of liquid fuel production technology becomes one of the pathways devoted to sustainable energy [1]. Fischer-Tropsch (F-T) synthesis is an attractive process for producing high-quality liquid fuels from syngas, derived from the gasification or reforming of coal, biomass, and natural gas [2]. Cobalt (Co) catalyst is very appealing for the F-T synthesis due to its high reactivity and high selectivity towards linear hydrocarbons, as well as the low activity for the water gas shift (WGS) reaction and acceptable prices [3]. Adequate support for the Co catalysts in F-T synthesis is alumina owing to its excellent texture, fine Co dispersions and superb attrition resistance [3]. Recently, mesoporous alumina (MA) earned considerable attention as catalyst support with its large surface area and porosity, which enabled the high dispersion of a significant number of catalytically active species [4].

One major issue associated with the alumina supported Co catalysts is that they show limited reducibility due to the strong interaction between the cobalt species and the alumina support. The reducibility of cobalt-based catalysts can be enhanced to some degree by promotion with a metal or metal oxide such as $\mathrm{Ru}, \mathrm{Pt}$, and $\mathrm{ZrO}_{2}$ [5]. To date, a plethora of studies have revolved around zirconia $(\mathrm{Zr})$ as a promoter for the supported cobalt catalyst. Zr promoted Co catalysts have been reported to enhance the catalytic activity and $\mathrm{C}_{5}+$ selectivity for the F-T synthesis compared with the non-promoted counterparts. Zhao et al. studied $\mathrm{Zr}$-promoted $\mathrm{Co} / \mathrm{SiO}_{2}$ catalysts and proposed that the promotion of $\mathrm{Zr}$ enhanced active sites at the interface between the Co metal and the $\mathrm{Zr}$ promoter atom, which improved turnover frequencies [6]. Also, $\mathrm{Zr}$ addition was reported could increase the cobalt cluster size and inhibit the formation of $\mathrm{CoAl}_{2} \mathrm{O}_{4}$, thus improving the activity and $\mathrm{C}_{5}+$ selectivity of $\mathrm{Co} / \mathrm{Al}_{2} \mathrm{O}_{3}$ catalysts [7]. The effect of pore size of the alumina support was investigated by $\mathrm{Ma}$ et al. and found that $\mathrm{Zr}$ primarily enhanced Co dispersion for the catalysts with wide pore size distribution while it mainly improved Co reduction for catalysts with very narrow pore size distribution [8].

The effects of different promoter incorporation methods on the catalytic performance in the F-T synthesis reactions have also been extensively investigated and reported in the literature. Zirconium's introduction into SBA-15 using four methods, impregnation, co-precipitation, isomorphic substitution (IS) and chemical grafting have been studied [9] [10]. They found that when IS was used to prepare zirconium modified SBA-15 supports, the cobalt catalysts showed higher activity than the one prepared by impregnation but lower activity than prepared by grafting. Following this, a range of cobalt catalysts supported on the isomorphically $\mathrm{Zr}$-substituted mesoporous SBA-15 with different $\mathrm{Zr} / \mathrm{Si}$ ratios have been investigated to elucidate the influence of $\mathrm{Zr}$ content [11]. It was found that the catalyst with a $\mathrm{Zr} / \mathrm{Si}$ ratio of $1 / 20$ showed the best performance in terms of activity and $\mathrm{C}_{5}+$ selectivity. However, $Z$ r's incorporation on MA supported cobalt catalysts for F-T synthesis, especially by the IS method, has not been explored in 
depth.

In the present work, a series of Co/MA catalysts with isomorphically substituted zirconium were synthesised. The catalysts prepared were characterised by $\mathrm{N}_{2}$ adsorption-desorption, XRD, TEM and XPS. F-T synthesis's catalytic performance was tested in a fixed bed reactor at $493 \mathrm{~K}$ and 20 bar. The effects of zirconium concentration in the mesoporous alumina structure were assessed in terms of catalyst activity and selectivity. In the meantime, $\mathrm{Zr}$ incorporated Co/MA catalysts with a $\mathrm{Zr} /(\mathrm{Zr}+\mathrm{Al})$ ratio of $5 \%$ prepared by wet impregnation method was used as a comparison to test the effects of $\mathrm{Zr}$ incorporation method on the catalyst performance.

\section{Experimental}

\subsection{Catalyst Preparation}

Isomorphically $\mathrm{Zr}$-substituted mesoporous alumina supports were synthesised via a sol-gel method [12]. The support was composite metal oxides with a formula of $\mathrm{x} \mathrm{mol} \% \mathrm{Zr}-\mathrm{y} \mathrm{mol} \% \mathrm{AlO}_{3 / 2}(\mathrm{x} \mathrm{mol} \%=\mathrm{nZr} /(\mathrm{nZr}+\mathrm{nAl}) \times 100 \%, \mathrm{x}+\mathrm{y}=$ 100 , denoted as MA-xZr(100-x)Al in the following text). Typically, $4.08 \mathrm{~g}(20$ $\mathrm{mmol}$ ) of aluminium isopropoxide (Sigma-Aldrich) was added into a flask with $36 \mathrm{~mL}(2 \mathrm{~mol})$ hot water $\left(85^{\circ} \mathrm{C}\right)$ to make a controlled hydrolysis ratio, $\mathrm{h}=$ $\left[\mathrm{H}_{2} \mathrm{O}\right] /[\mathrm{Al}]$, at 100 . After 15 minutes of vigorous stirring, another $0.097 \mathrm{ml}$ nitric acid $\left(\mathrm{HNO}_{3}, 70 \%,\left[\mathrm{HNO}_{3}\right] /[\mathrm{Al}]=0.07\right)$ was peptised into the flask, and the temperature of the suspension was increased to $85^{\circ} \mathrm{C}$ for $4 \mathrm{~h}$ to produce a transparent sol. The flask was kept uncovered for the first $1 \mathrm{~h}$ to allow the evaporation of isopropanol formed during the hydrolysis. After $4 \mathrm{~h}$, the zirconium nitrate (99\%, Sigma-Aldrich) and the Pluronic F127 template (Sigma-Aldrich) were then added to the sol, and the mixture was gently stirred for $24 \mathrm{~h}$ at room temperature. The sol was then dried in an oven at $70^{\circ} \mathrm{C}$ for $48 \mathrm{~h}$ to create the gel, followed by further calcination in air at $700^{\circ} \mathrm{C}$ for $3 \mathrm{~h}$ with a heating rate of 2 $\mathrm{K} / \mathrm{min}$. The resulting MA sample was ground using a pestle and mortar into a fine powder.

With a cobalt loading of $10 \mathrm{wt} \%$, the catalysts were also prepared using the wet impregnation method [3]. Cobalt nitrate (98\%, Sigma-Aldrich) of $1.95 \mathrm{~g}$ weight was dissolved in $10 \mathrm{ml}$ of ethanol and stirred until a clear solution was obtained. A cobalt salt solution was slowly added into $2 \mathrm{~g}$ of as-synthesised MA support powder and vigorously stirred at room temperature until the sample paste was formed. The sample paste was then dried at $110^{\circ} \mathrm{C}$ overnight and calcined in air at $300^{\circ} \mathrm{C}$ for $4 \mathrm{~h}$, respectively. The samples were labelled as $10 \mathrm{Co} /$ xZrMA-(s) with s stands for zirconium isomorphic substitution. For comparison, another cobalt catalyst supported on zirconium impregnated MA, was prepared by impregnating MA with an ethanol solution containing the desired amount of cobalt nitrate and zirconium nitrate with $\mathrm{Zr} / \mathrm{Si}$ atomic ratio of 0.05 . This catalyst was labelled as 10Co/5ZrMA-(i) with i stands for zirconium incorporated by a post-impregnation method. Meanwhile, commercial alumina ob- 
tained from Sigma-Aldrich was also used as a support to prepare a catalyst using the wet impregnation method described above, which was labelled as 10Co/ Com-A.

\subsection{Material Characterisation}

$\mathrm{N}_{2}$ physisorption was employed using a Tristar 3020 volumetric analyser (Micromeritics Co. Ltd) to determine the MA's surface area, pore-volume, and pore size distribution (PSD) supports and calcined catalysts. Before measurement, the samples were degassed in a vacuum at $200^{\circ} \mathrm{C}$ overnight to remove moisture and other absorbed species. The specific surface area was calculated from the adsorption data using the Brumauer-Emmett-Teller (BET) method in the relative pressure range of 0.05 - 0.30 [13]. The PSD was derived from the Barrett-JoynerHalenda $(\mathrm{BJH})$ calculations derived from desorption branches of the isotherms. The diameter of pore size $\left(D_{p}\right)$ was determined from the peak positions of the distribution curves. It should be pointed out that when $\mathrm{D}_{\mathrm{p}}$ reaches as high as about $20 \mathrm{~nm}$ with broad PSDs, these values reflect only an approximate mesopore maximum. The average pore diameter $\left(D_{a}\right)$ was determined by BET, and the pore volume $\left(\mathrm{V}_{\mathrm{p}}\right)$ was calculated by the $\mathrm{BJH}$ desorption cumulative volume of pores between $17 \AA$ and $3000 \AA$.

To determine the crystal phase of as-prepared MA supports and the active phase of cobalt, a powder X-ray diffraction analyser (Empyrean, PANalytical, $\mathrm{Cu}-\mathrm{Ka}$ radiation at $40 \mathrm{kV}, 40 \mathrm{~mA}$ ) was used to perform wide-angle X-ray scattering (WAXS) from $10^{\circ}$ to $80^{\circ}$ [14]. Furthermore, to ascertain the dispersion of active phases on the catalysts and their particle size, a transmission electron microscope (TEM) was obtained using a JEM-2100 JEOL electron microscope equipped with LaB6 filament operating at $120 \mathrm{kV}$ [15]. Samples were gently ground, dispersed in ethanol by moderate sonication and then deposited on a $\mathrm{Cu}$ grid (200 meshes). The samples were then allowed to dry in the air before imaging.

The surface composition of the catalysts was determined by X-ray photoelectron spectroscopy (XPS) using a Thermo ESCALAB 250 spectrometer with an Al $\mathrm{Ka}$ source $(1486.6 \mathrm{eV})$ at constant analyser pass energy of $20 \mathrm{eV}$ [16]. The binding energy (BEs) was estimated to be accurate within $0.1 \mathrm{eV}$. All binding energies were corrected by reference to the $\mathrm{C} 1 \mathrm{~s}(284.6 \mathrm{eV})$ peak of the contamination carbon and used as the internal standard. The Co $2 \mathrm{p}$ binding energy of the core level was determined by computer fitting of the measured spectra. The pressure of the analysis chamber was maintained at $5 \times 10^{-10} \mathrm{mbar}$.

\subsection{Evaluation of Catalyst Performance}

The catalysts were evaluated in Fischer-Tropsch (FT) synthesis in terms of CO conversion and selectivity (the percentage of the converted $\mathrm{CO}$ that appears as hydrocarbon products) in a high-pressure fixed-bed reactor. In a typical run, 0.4 $\mathrm{g}$ of powder catalyst was packed into a stainless reactor (I.D: $10 \mathrm{~mm}$ ) and re- 
duced in pure $\mathrm{H}_{2}$ at a flow rate of $45 \mathrm{ml} \cdot \mathrm{min}^{-1}$ under atmospheric pressure at 623 $\mathrm{K}$ for $10 \mathrm{~h}$. After the reduction, the reactor temperature was cooled down to 423 $\mathrm{K}$ under $\mathrm{N}_{2}$ flow. Then the reactant gas mixture (in an $\mathrm{H}_{2}$ : $\mathrm{CO}$ :Ar volume ratio of 6:3:1, Ar used as the internal standard) was introduced from the top of the reactor at a flow rate of $30 \mathrm{ml} \cdot \mathrm{min}^{-1}$, and the reactor pressure was increased to 20 bar. The reactor temperature was then increased at a rate of $1 \mathrm{~K} \cdot \mathrm{min}^{-1}$ from 423 to $493 \mathrm{~K}$. The selection of the very low heating rate is to avoid any catalyst bed temperature surge due to the highly exothermic nature of F-T. The synthesis was carried out for $20 \mathrm{~h}-24 \mathrm{~h}$ to ensure the stabilisation of catalyst activity.

The reactor's effluent was allowed to pass through and dissolved in a trap containing $25 \mathrm{~mL}$ of ethyl acetate cooled with ice, in which liquid oil and solid wax products were collected. Next, the gas stream was analysed on-line at a $2 \mathrm{~h}$ interval by an Agilent 7890 A gas chromatograph (GC) equipped with a Gas-Pro capillary column, a Hayesep Q column, a molecular sieve $5 \AA$ capped columns, a flame ionisation detector (FID), and a thermal conductivity detector (TCD). The $\mathrm{C}_{5}+$ products collected in the ethyl acetate trap were analysed by another off-line Agilent 7890 A gas chromatograph equipped with an HP-5 column and an FID.

\section{Results and Discussion}

The $\mathrm{N}_{2}$ adsorption-desorption isotherms of the supports are shown in Figure 1(a). All the nitrogen adsorption-desorption isotherms of MA support, whether pure MA or promoted with Zr, displayed typical type IV with an obvious $\mathrm{H} 1$ hysteresis loop at high relative pressure, indicating the presence of mesoporous in the supports [17] [18]. However, with the increase of the $\mathrm{Zr} /(\mathrm{Zr}+\mathrm{Al})$ molar ratio, the isotherms became narrower, suggesting that the alumina's mesoporous structure was affected by the increasing $\mathrm{Zr}$ content [19].

Moreover, pore size distribution curves showed the $\mathrm{Zr}$ incorporated MA supports have quite narrow pore size distributions (PSD) ranging from $2 \mathrm{~nm}$ to 50 $\mathrm{nm}$, as shown in Figure 1(b). For Com-A, the BET surface area, pore volume $(\mathrm{Vp})$ and average pore diameter $(\mathrm{Dp})$ were smaller than its mesoporous counterparts, with which these parameters decreased with increasing $\mathrm{Zr} /(\mathrm{Zr}+\mathrm{Al})$ atomic ratio (Table 1). Remarkable BET surface area and pore volume decreased was noticed when the $\mathrm{Zr} /(\mathrm{Zr}+\mathrm{Al})$ atomic ratio exceeded $5 \%$, suggesting the possible collapse of the mesoporous structure during the synthesis and subsequent calcination process due to the high content of Zr. Moreover, the pore size and pore volume reduced gradually as the $\mathrm{Zr} /(\mathrm{Zr}+\mathrm{Al})$ atomic ratio increased, indicating the possible blocking to mesoporous channels due to the formation of single $\mathrm{ZrO}_{2}$ particles outside the mesostructure.

The $\mathrm{N}_{2}$ adsorption-desorption isotherms of the catalysts are shown in Figure 2(a). The isotherms of the MA supported catalysts still showed the H1 hysteresis loop, indicating they retained the mesoporous structure. However, the isotherms were broader, suggesting the mesoporosity decreased due to Co's deposition onto the surface of supports. This result is in line with the results shown in Figure 2(b), in which the PSD curves broadened after Co loading. As expected, the 


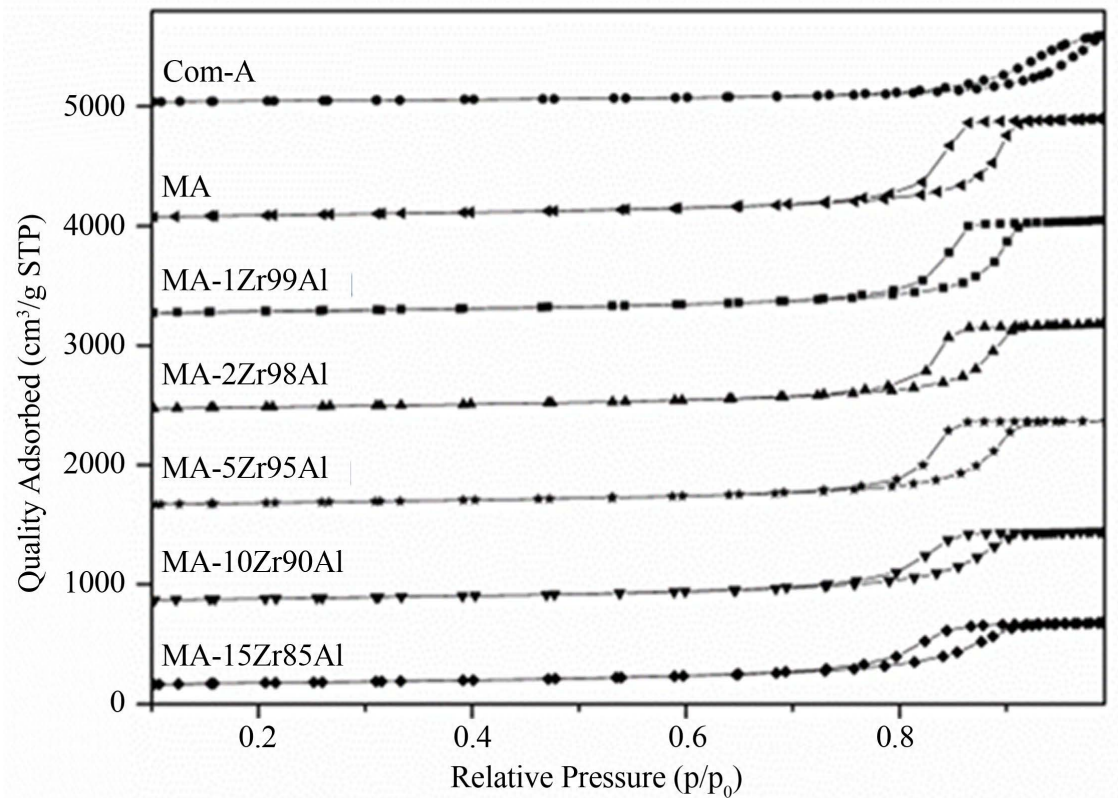

(a)

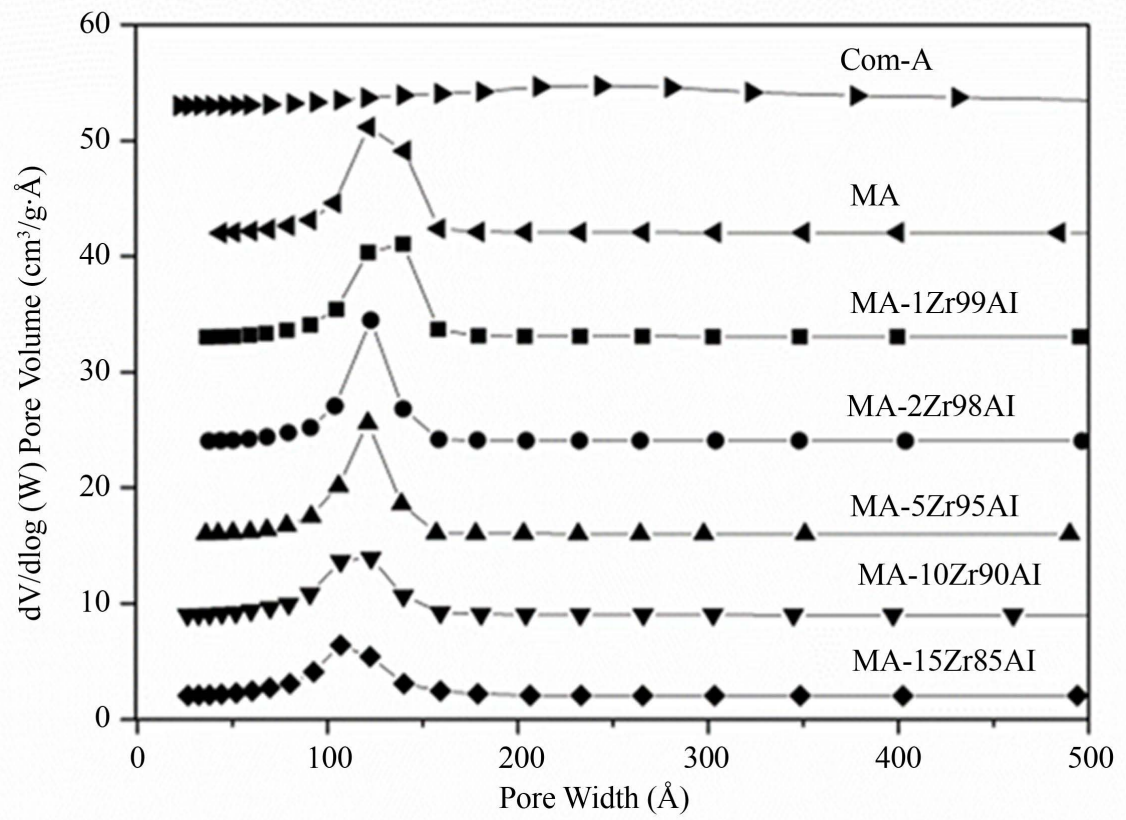

(b)

Figure 1. Nitrogen adsorption-desorption isotherms (a) and BJH pore size distribution (b) of supports.

BET surface area, $V_{p}$ and $D_{p}$ of all the catalysts were smaller than their support's corresponding values (Table 1 ). The BET surface area, $\mathrm{V}_{\mathrm{p}}$ and $\mathrm{D}_{\mathrm{p}}$ of $10 \mathrm{Co} /$ $5 \mathrm{ZrAl}-(\mathrm{s})$ were larger than $10 \mathrm{Co} / 5 \mathrm{ZrAl}$-(i). It shows that alumina's mesoporous structure was better preserved when the sample was prepared by isomorphic substitution.

As seen from the XRD patterns shown in Figure 3(a), all the supports, with and without $\mathrm{Zr}$ incorporation, showed a group of diffraction maxima at $45.8^{\circ}$, $67.0^{\circ}, 37.6^{\circ}$, which was assigned to the diffraction of $\gamma$-alumina [400], [440] and 


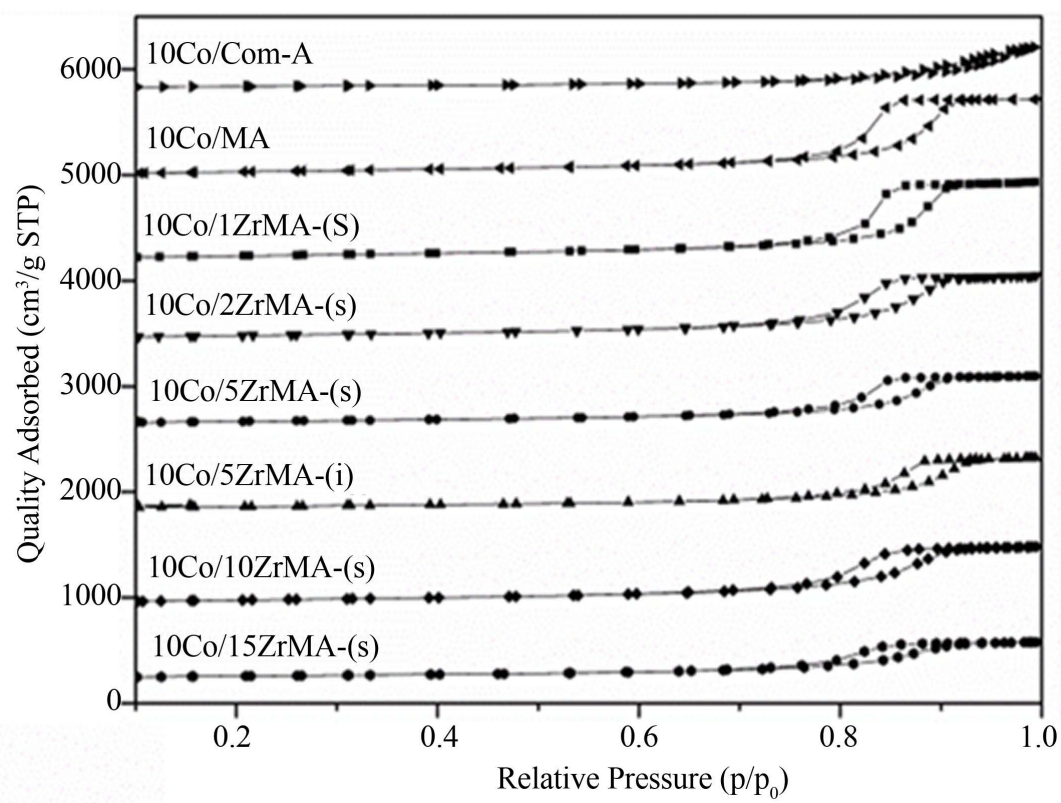

(a)

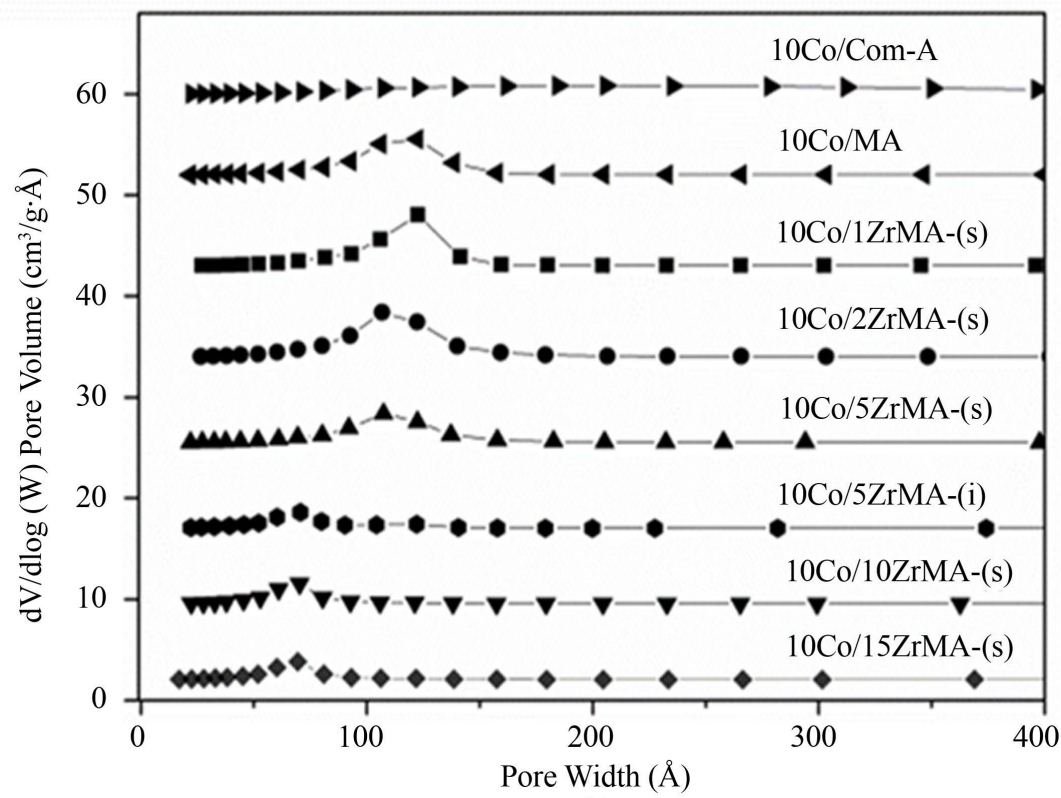

(b)

Figure 2. Nitrogen adsorption-desorption isotherms (a) and BJH pore size distribution (b) of catalysts.

[311] faces (JCPDS Card No. 10-0425). It is worth noting that for supports with a $\mathrm{Zr} /(\mathrm{Zr}+\mathrm{Al})$ atomic ratio lower than $5 \%$, the characteristic diffraction maxima of zirconium compounds were not observed, suggesting that zirconium was well dispersed in the alumina matrix [20]. When the $\mathrm{Zr} /(\mathrm{Zr}+\mathrm{Al})$ atomic ratio was higher than $5 \%$, the characteristic diffraction maxima linked to the tetragonal $\mathrm{ZrO}_{2}$ phase were observed. The diffraction maxima intensity of the tetragonal $\mathrm{ZrO}_{2}$ phase increased with the increase of $\mathrm{Zr} /(\mathrm{Zr}+\mathrm{Al})$ ratio. It indicates that isolated tetragonal $\mathrm{ZrO}_{2}$ particles formed on the catalyst's surface [21]. These 
Table 1. Adsorption parameters of supports and catalysts.

\begin{tabular}{cccc}
\hline Sample & $\begin{array}{c}\text { BET Surface } \\
\mathrm{Area}^{\mathrm{a}}\left(\mathrm{m}^{2} / \mathrm{g}\right)\end{array}$ & $\begin{array}{c}\text { Pore Volume } \\
\mathrm{Vp}^{\mathrm{b}}\left(\mathrm{cm}^{3} / \mathrm{g}\right)\end{array}$ & $\begin{array}{c}\text { Pore Diameter } \\
\mathrm{Dp}^{\mathrm{c}}(\mathrm{nm})\end{array}$ \\
\hline Com-Al & 150.0 & 0.91 & - \\
MA-1Zr99Al & 268.9 & 1.48 & 13.3 \\
MA-2Zr98Al & 236.6 & 1.26 & 13.0 \\
MA-5Zr95Al & 220.2 & 1.15 & 12.4 \\
MA-10Zr90Al & 206.3 & 1.09 & 12.0 \\
MA-15Zr85Al & 193.4 & 1.02 & 11.4 \\
10Co/Com-A & 180.5 & 0.97 & - \\
10Co/MA & 80.1 & 0.72 & 10.8 \\
10Co/1ZrMA-(s) & 238.4 & 1.29 & 10.3 \\
10Co/2ZrMA-(s) & 220.6 & 1.17 & 10.0 \\
10Co/5ZrMA-(s) & 202.2 & 1.02 & 10.1 \\
10Co/5ZrMA-(i) & 193.3 & 0.93 & 7.5 \\
10Co/10ZrMA-(s) & 179.4 & 0.84 & 7.2 \\
10Co/15ZrMA-(s) & 161.3 & 0.82 & 0.77 \\
\hline
\end{tabular}

${ }^{a} \mathrm{BET}$ surface area measured in the relative pressure range of $0.05-0.30$; ${ }^{\mathrm{b}} \mathrm{The} \mathrm{BJH}$ desorption cumulative volume of pores between $17 \AA$ and $3000 \AA$ wide; ${ }^{\mathrm{c}}$ The peak positions of the distribution curves by $\mathrm{BJH}$.

results are in good agreement with the $\mathrm{N}_{2}$ adsorption-desorption and could also explain the surface area and pore size decrease, as mentioned in Table 1. When the support was loaded with Co catalyst, the spinel phases of $\mathrm{Co}_{3} \mathrm{O}_{4}$ and the different crystal phases of $\mathrm{Co}_{3} \mathrm{O}_{4}-\mathrm{Al}_{2} \mathrm{O}_{3}$ species, including $\mathrm{CoAl}_{2} \mathrm{O}_{4}$ were observed, as shown in Figure 3(b). However, diffraction maxima for the tetragonal $\mathrm{ZrO}_{2}$ phase were not observed, possibly because they were masked by other relatively strong diffraction maxima.

The transmission electron micrographs of the catalysts are shown in Figure 4. It can be seen that different from the Com-A supported Co catalyst, and all MA supported Co samples showed wormhole-like pores. There was no significant difference in morphology between the MA and Zr-modified MA supported catalysts. However, as the $\mathrm{Zr} /(\mathrm{Zr}+\mathrm{Al})$ atomic ratio increased, the co-species agglomeration became more pronounced.

The XPS data are shown in Table 2 and Figure 5, indicates that the 10Co/ Com-A catalyst showed the highest binding energy (BE) for Co $2 \mathrm{p}_{3 / 2}(781.78 \mathrm{eV})$ while 10Co/5ZrMA-(s) had the lowest $(780.42 \mathrm{eV})$. The Co $2 \mathrm{p}_{3 / 2}$ BEs of the MA supported catalysts noticeably decreased with increasing $\mathrm{Zr} /(\mathrm{Zr}+\mathrm{Al})$ atomic ratio but remained in the region of $780.42 \mathrm{eV}$ for $10 \mathrm{Co} / 5 \mathrm{ZrMA}-(\mathrm{s})$ and 


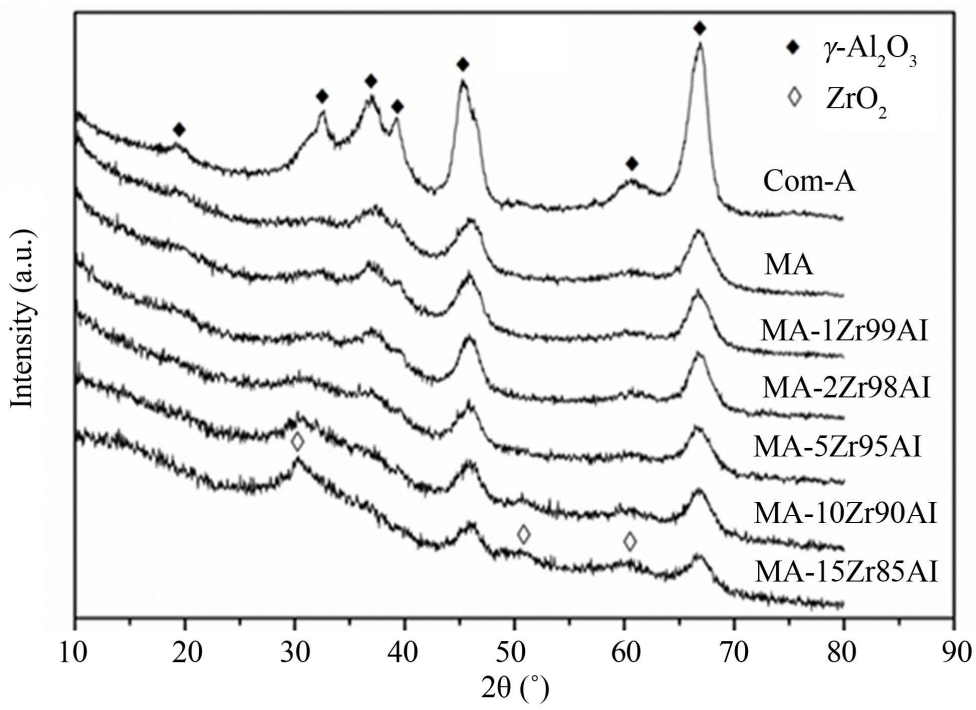

(a)

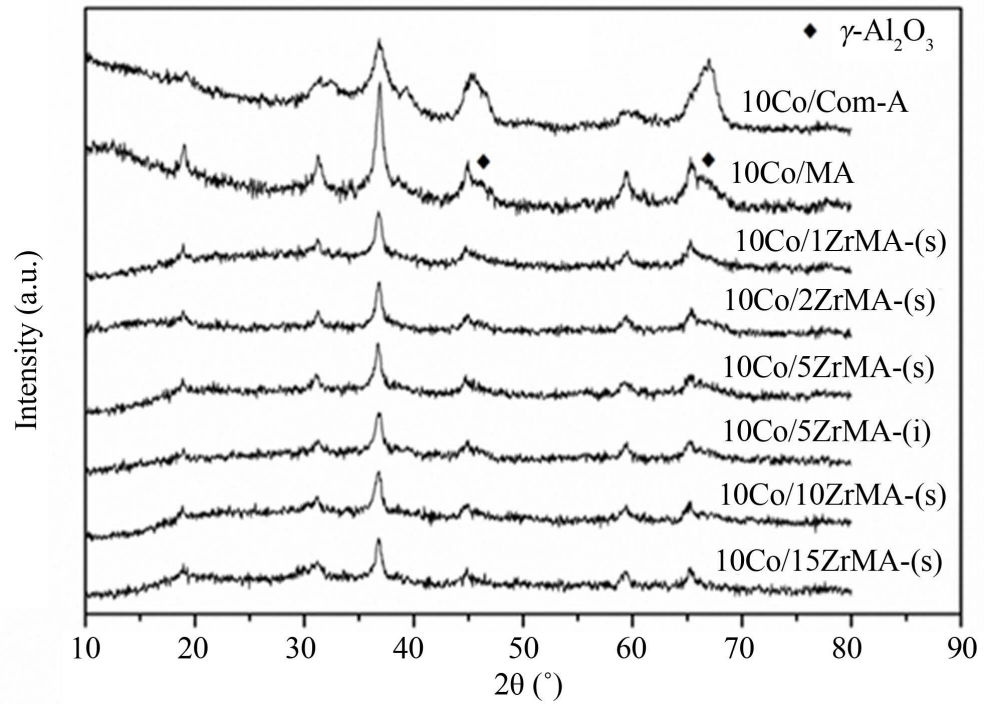

(b)

Figure 3. Powder XRD patterns of supports (a) and catalysts (b).

Table 2. Co $2 \mathrm{p}_{3 / 2}$ binding energy (BE) of different catalysts.

\begin{tabular}{cc}
\hline Catalyst & Co $2 \mathrm{p}_{3 / 2} \mathrm{BE}(\mathrm{eV})$ \\
\hline $10 \mathrm{Co} /$ Com-A & 781.45 \\
$10 \mathrm{Co} / \mathrm{MA}$ & 781.04 \\
10Co/1ZrMA-(s) & 780.97 \\
10Co/2ZrMA-(s) & 780.86 \\
10Co/5ZrMA-(s) & 780.52 \\
10Co/5ZrMA-(i) & 780.83 \\
10Co/10ZrMA-(s) & 780.66 \\
$10 \mathrm{Co} / 15 Z$ rMA-(s) & 780.77 \\
\hline
\end{tabular}



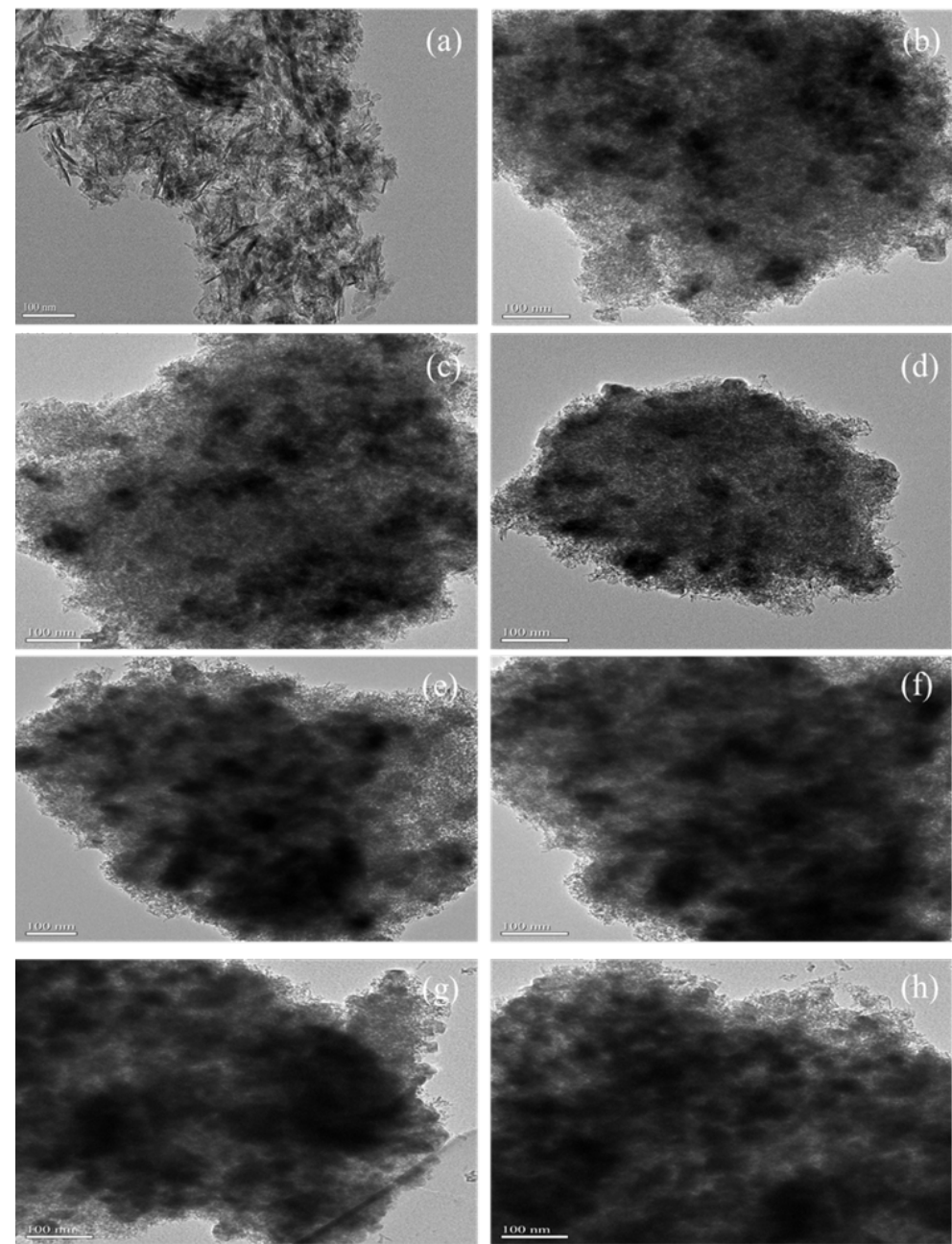

Figure 4. TEM images of catalysts: 10Co/Com-A (a), 10Co/MA (b), 10Co/1ZrMA-(s) (c), 10Co/2ZrMA-(s) (d), 10Co/5ZrMA-(s) (e), 10Co/5ZrMA-(i) (f), 10Co/10ZrMA-(s) (g), 10Co/15ZrMA-(s) (h).

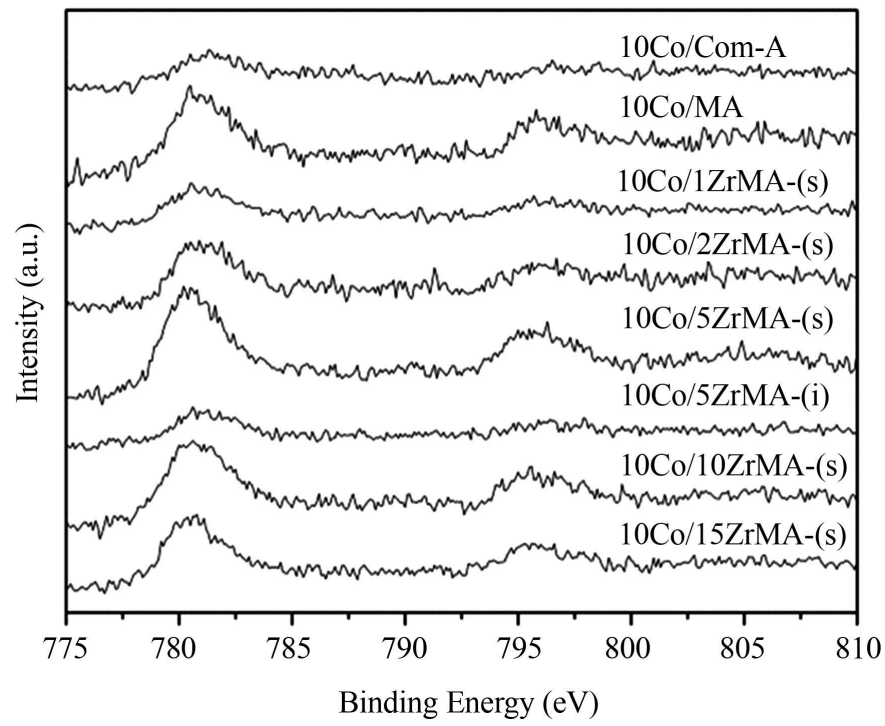

Figure 5. XPS spectra of the Co $2 \mathrm{p}$ level for catalysts. 
$781.04 \mathrm{eV}$ for $10 \mathrm{Co} / \mathrm{MA}$. This suggests that the main phase on the catalyst's surface was $\mathrm{Co}_{3} \mathrm{O}_{4}$, which is in good agreement with the XRD results. The BE for $10 \mathrm{Co} / \mathrm{Com}-\mathrm{A}$ was higher than that of pure $\mathrm{Co}_{3} \mathrm{O}_{4}(\mathrm{BE}=780.3 \mathrm{eV})$, indicating the formation of cobalt-alumina phase on the catalyst surface [22].

Notably, the XPS spectra show that with increasing $\mathrm{Zr}$ content, the Co $2 \mathrm{p}_{3 / 2}$ region was shifted to a lower $\mathrm{BE}$ value. It suggests that Zr's addition inhibited the formation of the cobalt surface phase. Therefore, the interaction between the cobalt species and the alumina support was possibly suppressed [7] [8]. However, as further increasing $\mathrm{Zr}$ content (10Co/10ZrMA-(s) and 10Co/15ZrMA-(s)) or for the catalysts prepared by wet impregnation (10Co/5ZrMA-(i)), the Co $2 \mathrm{p}_{3 / 2}$ peak shifted toward relatively higher $\mathrm{BE}$, suggesting the interaction between cobalt species and supports had increased.

The results of F-T synthesis activity and product selectivity of the catalysts are summarised in Table 3. As expected, the CO conversion of 10Co/Com-A was the lowest among catalysts under the same conditions, attributed to the lowest surface area, pore volume and reducibility of the cobalt species in the catalysts. It can be seen that $\mathrm{CO}$ conversion increased with the increase of $\mathrm{Zr}$ content from 0 to $5 \%$, and then decreased with a further increase from $5 \%$ to $15 \%$. In theory, reduced cobalt catalysts activity depends on the concentration of surface metal cobalt sites [23]. In this study, when $\mathrm{Zr}^{4+}$ ions were introduced into the alumina framework of MA to support Co particles, they created and retained a relatively high surface area and large pore volume, leading to the high probability of $\mathrm{Zr}^{4+}$ ions contacting $\mathrm{Co}_{3} \mathrm{O}_{4}$ particles. With increasing $\mathrm{Zr}$ content, the extent of $\mathrm{Co}$ reduction increased, forming more accessible cobalt active surface sites and thus higher $\mathrm{CO}$ conversion. However, when the $\mathrm{Zr} /(\mathrm{Zr}+\mathrm{Al})$ atomic ratio increased from $5 \%$ to $15 \%$, the mesostructure was destroyed, giving rise to a decrease in the surface area and pore volume (Table 1). As a result, the interaction between

Table 3. Performance of the as-synthesised catalysts in F-T synthesis.

\begin{tabular}{|c|c|c|c|c|c|c|c|}
\hline \multirow{2}{*}{ Catalyst } & \multirow{2}{*}{$\begin{array}{c}\text { CO conv. } \\
(\%)^{\mathrm{a}}\end{array}$} & \multicolumn{5}{|c|}{ Product distribution (wt.\%) } & \multirow{2}{*}{$\alpha^{\mathrm{b}}$} \\
\hline & & $\mathrm{C}_{1}$ & $\mathrm{C}_{2}-\mathrm{C}_{4}$ & $\mathrm{C}_{5}-\mathrm{C}_{9}$ & $\mathrm{C}_{10}-\mathrm{C}_{20}$ & $\mathrm{C}_{21}+$ & \\
\hline $10 \mathrm{Co} / \mathrm{Com}-\mathrm{A}$ & 20.4 & 25.2 & 23.5 & 22.3 & 23.6 & 5.4 & 0.67 \\
\hline $10 \mathrm{Co} / \mathrm{MA}$ & 25.6 & 15.6 & 20.1 & 27.3 & 29.5 & 7.5 & 0.71 \\
\hline 10Co/1ZrMA-(s) & 27.5 & 11.6 & 18.1 & 29.4 & 32.3 & 8.6 & 0.75 \\
\hline 10Co/2ZrMA-(s) & 35.4 & 9.1 & 15.2 & 30.7 & 33.4 & 11.6 & 0.79 \\
\hline 10Co/5ZrMA-(s) & 38.9 & 7.7 & 11.0 & 31.7 & 34.6 & 15.0 & 0.80 \\
\hline 10Co/5ZrMA-(i) & 26.8 & 14.4 & 18.7 & 28.2 & 30.7 & 8.0 & 0.72 \\
\hline 10Co/10ZrMA-(s) & 29.7 & 10.3 & 16.1 & 30.1 & 32.8 & 10.7 & 0.74 \\
\hline 10Co/15ZrMA-(s) & 28.3 & 13.7 & 18.2 & 28.8 & 31.0 & 8.3 & 0.78 \\
\hline
\end{tabular}

a Reaction conditions: $493 \mathrm{~K}, 20$ bar, $\mathrm{H}_{2} / \mathrm{CO}=2$, feed flow rate $=30 \mathrm{ml} \cdot \mathrm{min}^{-1}$. ${ }^{\mathrm{b}}$ Chain-growth probability $(\alpha)$ obtained from the ASF plot in the $\mathrm{C}_{8}-\mathrm{C}_{14}$ hydrocarbons range. 
the cobalt species and the supports was weakened, leading to a decrease in cobalt reduction and thus lower $\mathrm{CO}$ conversion. It is also evident that at the same $\mathrm{Zr}$ level, the CO conversion of the 10Co/5ZrMA-(s) prepared by isomorphic substitution was higher than $10 \mathrm{Co} / 5 \mathrm{ZrMA}$-(i) prepared by wet impregnation.

Regarding product selectivity, 10Co/Com-A gave the highest methane selectivity and the lowest diesel $\left(\mathrm{C}_{10}-\mathrm{C}_{20}\right)$ selectivity (Table 3 ). For MA supported catalysts with $\mathrm{Zr}$ incorporation, methane selectivity decreased from $15.6 \%$ to 7.5\% when $\mathrm{Zr}$ content increased from zero to $5 \%$ and increased with further increase in the $\mathrm{Zr}$ content. On the other hand, diesel selectivity was relatively constant with the increase of $\mathrm{Zr}$ content. When the 10Co/5ZrMA-(s) and 10Co/ 5ZrMA-(i) were compared, the former showed lower methane selectivity and higher diesel selectivity than the latter, indicating its advantage $\mathrm{Zr}$ incorporation to MA through the IS method for diesel production. High methane selectivity was usually found over catalysts with low cobalt reducibility and surface area [24]. The formation of unreduced cobalt oxides catalysed the WGS reaction. As shown in XPS data, the 10Co/Com-A exhibited a strong interaction between the cobalt species and the supports and small surface area, which would result in the low reducibility of cobalt species, resulted in high methane selectivity. By contrast, when $\mathrm{Zr}$ was added, the interaction of the cobalt species with the supports was initially suppressed (XPS data in Figure 5) up to $\mathrm{Zr} /(\mathrm{Zr}+\mathrm{Al})$ atomic ratio of $5 \%$, but then enhanced when the $\mathrm{Zr} /(\mathrm{Zr}+\mathrm{Al})$ atomic ratio was further increased up to $10 \%$. The higher diesel selectivity of all MA supported samples could also be attributed to the space confinement effect of mesoporous, which enhanced the re-adsorption of the $\alpha$-olefin intermediates produced during the reaction further enhanced chain growth [22].

\section{Conclusion}

Isomorphic $\mathrm{Zr}$ substitution in mesoporous alumina (MA) support did not affect the structural integrity and properties of the parent MA at low zirconium contents. However, when the $\mathrm{Zr} /(\mathrm{Zr}+\mathrm{Al})$ ratio was higher than $5 \%$, a partial collapse of the mesostructure was incurred. For the MA supported Co catalysts used in $\mathrm{F}-\mathrm{T}$ synthesis, by introducing low levels of $\mathrm{Zr}(\mathrm{Zr} /(\mathrm{Zr}+\mathrm{Al})$ ratio $<5 \%)$, the interaction of Co species with the support was suppressed, facilitating the reduction of cobalt oxides and increasing the $\mathrm{CO}$ conversion and diesel $\left(\mathrm{C}_{10}\right.$ $\mathrm{C}_{20}$ ) selectivity. However, when further increasing $\mathrm{Zr} /(\mathrm{Zr}+\mathrm{Al})$ ratio from $5 \%$, the $\mathrm{CO}$ conversion and diesel selectivity dropped. It was possibly due to the depreciation of cobalt reducibility caused by the reduction of surface area and pore volume. All MA supported catalysts showed better catalytic performance than the Com-A supported catalyst without mesoporous structure. Compared to the wet impregnation method, the isomorphic substitution method was better in $\mathrm{CO}$ conversion and diesel selectivity.

\section{Acknowledgements}

The authors wish to thank Mr. Wan Chen for assistance with the experimental 
work, data collection and analysis. The Australian Renewable Energy Agency (2018/RND013), Australian Research Council (ARC LP100200136), and Chevron Energy Technology Pty Ltd. are acknowledged for partial financial support. The authors also acknowledge the facilities, and the technical assistance of the Australian Microscopy \& Microanalysis Research Facility at the Centre for Microscopy, Characterisation \& Analysis, The University of Western Australia.

\section{Conflicts of Interest}

The authors declare no conflicts of interest regarding the publication of this paper.

\section{References}

[1] Bykova, E. (2016) Short-Term Outlook on Fuel and Energy Balance in the Analysis of Energy Security. International Journal of Energy for a Clean Environment, 17, 295-302. https://doi.org/10.1615/InterJEnerCleanEnv.2017019361

[2] Lillebø, A.H., Anders Holmen A., Enger, B.C. and Blekkan, E.A. (2013) Fischer-Tropsch Conversion of Biomass-Derived Synthesis Gas to Liquid Fuels. WIREs Energy and Environment, 2, 507-524. https://doi.org/10.1002/wene.69

[3] Khodakov, A.Y., Chu, W. and Fongarland, P. (2007) Advances in the Development of Novel Cobalt Fischer-Tropsch Catalysts for Synthesis of Long-Chain Hydrocarbons and Clean Fuels. Chemical Reviews, 107, 1692-1744. https://doi.org/10.1021/cr050972v

[4] Linares, N., Silvestre-Albero, A.M., Serrano, E., Silvestre-Albero, J. and GarciaMartınez, J. (2014) Mesoporous Materials for Cleanenergy Technologies. Chemical Society Reviews, 43, 7681-7717. https://doi.org/10.1039/C3CS60435G

[5] Zhang, Q., Kang, J. and Wang, Y. (2010) Development of Novel Catalysts for Fischer-Tropsch Synthesis: Tuning the Product Selectivity. ChemCatChem, 2, 1030-1058. https://doi.org/10.1002/cctc.201000071

[6] Zhao, Y., Sohn, H., Hu, B., Niklas, J., Poluektov, O.G., Tian, J., Delferro, M. and Hock, A.S. (2018) Zirconium Modification Promotes Catalytic Activity of a Single-Site Cobalt Heterogeneous Catalyst for Propane Dehydrogenation. ACS Omega, 3, 11117-11127. https://doi.org/10.1021/acsomega.8b00862

[7] Xiong, H., Zhang, Y.H., Liew, K.Y. and Li, J.L. (2005) Catalytic Performance of Zirconium-Modified $\mathrm{CO} / \mathrm{Al}_{2} \mathrm{O}_{3}$ for Fischer-Tropsch Synthesis. Journal of Molecular Catalysis A: Chemical, 231, 145-151. https://doi.org/10.1016/j.molcata.2004.12.033

[8] Ma, W.P., Jacobs, G., Gao, P., Jermwongratanachai, T., Shafer, W.D., Pendyla, P.R.R., Yen, C.H., Klettlinger, J.L.S. and Davis, B.H. (2014) Fischer-Tropsch Synthesis: Pore Size and Zr Promotional Effects on the Activity and Selectivity of 25\% $\mathrm{Co} / \mathrm{Al}_{2} \mathrm{O}_{3}$ Catalysts. Applied Catalysis A: General, 475, 314-324. https://doi.org/10.1016/j.apcata.2014.01.016

[9] Liu, Y.Y., Murata, K., Okabe, K., Hanaoka, T. and Sakanishi, K. (2008) Synthesis of Zr-Grafted SBA-15 as an Effective Support for Cobalt Catalyst. Chemistry Letters, 37, 984-985. https://doi.org/10.1246/cl.2008.984

[10] Mu, S.F., Li, D.B., Hou, B., Jia, L.H., Chen, J.G. and Sun, Y.H. (2010) Influence of $\mathrm{ZrO}_{2}$ Loading on SBA-15-Supported Cobalt Catalysts for Fischer-Tropsch Synthesis. Energy Fuels, 24, 3715-3718. https://doi.org/10.1007/s11426-010-4165-y

[11] Tao, C.L., Li, J.L., Zhang, Y.H. and Liew, K.Y. (2010) Effect of Isomorphic Substitu- 
tion of Zirconium on Mesoporous Silica as Support for Cobalt Fischer-Tropsch Synthesis Catalysts. Journal of Molecular Catalysis A: Chemical, 331, 50-57. https://doi.org/10.1016/j.molcata.2010.08.002

[12] Wu, W., Wan, Z.J., Chen, W., Yang, H. and Zhang, D.K. (2014) A Facile Synthesis Strategy for Structural Property Control of Mesoporous Alumina and Its Effect on Catalysis for Biodiesel Production. Advanced Powder Technology, 25, 1220-1226. https://doi.org/10.1016/j.apt.2014.06.005

[13] Lowell, S., Shields, J.E., Thomas, M.A. and Thommes, M. (2004) Characterisation of Porous Solids and Powders: Surface Area, Pore Size and Density. Springer, Dordrecht. https://doi.org/10.1007/978-1-4020-2303-3

[14] Pecharsky, V.K. and Zavalij, P.Y. (2009) Fundamentals of Powder Diffraction and Structural Characterisation of Materials. 2nd Edition, Springer, Boston.

https://doi.org/10.1007/978-0-387-09579-0

[15] Williams, D.B. and Carter, C.B. (2009) Transmission Electron Microscopy-A Textbook for Materials Science. Springer, Boston. https://doi.org/10.1007/978-0-387-76501-3

[16] Watts, J.F. and Wolstenholme, J. (2003) An Introduction to Surface Analysis by XPS and AES. 2nd Edition, John Wiley \& Sons, Inc., Hoboken. https://doi.org/10.1002/9781119417651

[17] Dutt, M., Kaushik, A., Tomar, M., Gupta, V. and Singh, V. (2020) Synthesis of Mesoporous $\alpha-\mathrm{Fe}_{2} \mathrm{O}_{3}$ Nanostructures via Nanocasting Using MCM-41 and KIT-6 as Hard Templates for Sensing Volatile Organic Compounds (VOCs). Journal of Porous Materials, 27, 285-294. https://doi.org/10.1007/s10934-019-00811-0

[18] Cai, W., Yu, J., Anand, C., Vinu, A. and Jaroniec, M. (2011) Facile Synthesis of Ordered Mesoporous Alumina and Alumina-Supported Metal Oxides with Tailored Adsorption and Framework Properties. Chemistry of Materials, 23, 1147-1157. https://doi.org/10.1021/cm102512v

[19] Tao, C.L., Li, J.L. and Liew, K.Y. (2010) Effect of the Pore Size of Co/SBA-15 Isomorphically Substituted with Zirconium on Its Catalytic Performance in Fischer-Tropsch Synthesis. Science China Chemistry, 53, 2551-2559. https://link.springer.com/article/10.1007/s11426-010-4165-y

[20] Wei, M.D., Okabe, K., Arakawa, H. and Teraoka, Y. (2004) Synthesis and Characterisation of Zirconium Containing Mesoporous Silicates and the Utilisation as Support of Cobalt Catalysts for Fischer-Tropsch Synthesis. Catalysis Communications, 5, 597-603. https://doi.org/10.1016/j.catcom.2004.07.014

[21] Lam, E., Larmier, K., Wolf, P., Tada, S., Safonova, O.V. and Copéret, C. (2018) Isolated $\mathrm{Zr}$ Surface Sites on Silica Promote Hydrogenation of $\mathrm{CO}_{2}$ to $\mathrm{CH}_{3} \mathrm{OH}$ in Supported Cu Catalysts. Journal of the American Chemical Society, 140, 10530-10535. https://doi.org/10.1021/jacs.8b05595

[22] Xiong, H., Zhang, Y., Wang, S., Liew, K. and Li, J. (2008) Preparation and Catalytic Activity for Fischer-Tropsch Synthesis of Ru Nanoparticles Confined in the Channels of Mesoporous SBA-15. The Journal of Physical Chemistry C, 112, 9706-9709. https://doi.org/10.1021/jp800579v

[23] Zhang, Q., Cheng, K., Kang, J., Deng, W. and Wang, Y. (2014) Fischer-Tropsch Catalysts for the Production of Hydrocarbon Fuels with High Selectivity. ChemSusChem, 7, 1251-1264. https://doi.org/10.1002/cssc.201300797

[24] James, O.O., Chowdhury, B., Mesubi, M.A. and Maity, S. (2012) Reflections on the Chemistry of the Fischer-Tropsch Synthesis. RSC Advances, 2, 7347-7366. https://doi.org/10.1039/C2RA20519J 